\title{
Loved Ones Near and Far: Feinberg's Personal Significance Theory
}

\author{
Commentary by William Hirstein (Elmhurst, IL)
}

\begin{abstract}
Todd Feinberg's personal significance theory offers a coherent and unified explanation for the misidentification syndromes, such as Capgras syndrome, as well as certain body-image disorders, such as asomatognosia and somatoparaphrenia. This reply offers several criticisms directed toward sharpening the theory. First, personal significance is still a broad and indistinct concept, and most of the representations in our brains are of people and things of personal significance to us. Second, the idea that the Capgras patient has lost his sense of personal significance for, for example, his parents, does not explain why he believes they are impostors. A more specific hypothesis directed toward explaining this is that Capgras syndrome involves a type of mindreading disorder, in which the patient's representation of his parents' minds and personalities is damaged or inaccessible to his cognition. If we assume that our representations of peoples' external features can become disconnected from our representations of their internal, mental features, this is exactly the sort of thing that would produce the appearance of an impostor. Third, the two-factor account of delusions offers a plausible competitor to Feinberg's approach. According to it, Capgras syndrome is caused by two sites of damage in the brain, one that affects the way the person appears to the patient, and a second, frontal site of damage that affects the patient's rationality in such a way that he does not notice the gross implausibility of the impostor claim.
\end{abstract}

Keywords: misidentification syndromes; Capgras syndrome; mindreading; temporoparietal junction; executive processes; confabulation

Synthesizing data from his extensive clinical experience, cognitive neuropsychology, and the theories of Freud, Todd Feinberg has made an impressive attempt to explain a diverse set of strange and seemingly intractable syndromes. These include the misidentification syndromes, as well as asomatognosia and its more severe variant, somatoparaphrenia. In what follows, I will make several comments and criticisms directed toward the improvement of Feinberg's approach.

\section{Personal significance}

These disorders are to be viewed as malfunctions in the brain's systems for representing and tracking people and things of personal significance, according to Feinberg. Something is of personal significance to a patient if it makes specific reference to personal identity, sense of self, the personal significance of self to others or how the individual expresses their specifically personal and autobiographical history. There are two principle weaknesses in the personal significance hypothesis. First, the notion of personal significance is too broad as it stands - that is, it does not specify a small enough set of brain states. The majority of representations in our brains meet this description. Second, it does not give a specific explanation for the content of the Capgras delusion: that the familiar person is an

William Hirstein: Department of Philosophy and the Cognitive Science Laboratory, Elmhurst College, Elmhurst, Illinois, U.S.A. impostor. Why do so many different patients, with different backgrounds, different personalities, and different comorbidity, all produce the same highly unlikely story? Why don't they say, "Dad seems strange to me," "I don't have any feelings for Dad any more," or "Dad has changed in some way"?

Feinberg also seems to overlook an important distinction between representing something as literally me or a part of me (e.g., my arm) and representing something as very closely related to me (e.g., a spouse). The presence of "mixed" patients, who show both an increase and a decrease in their senses of personal relatedness for an object or person, is also troubling, since it indicates that the patients do not line up neatly on a single personal relatedness continuum. It seems more plausible that a patient would either tend to push people outside the circle of the personally related, or bring them in, but not both. One way to respond to these criticisms would be to further specify the mechanism that allows both types while affecting only representations of personally related people or objects.

To claim that someone is not your father but, rather, someone posing as your father is to make a claim about the identity of that person, and also to disavow the personal relatedness of that person. Logically, the identity of someone is independent of that person's degree of personal relatedness to us, but in practicality, when the identity of loved ones is at stake, alterations in perceived identity will also involve alterations in perceived personal relatedness. Conversely, alterations in the patient's sense of personal relatedness need not also involve alternations in perceived identity. One might 
experience a loss in the sense of personal relatedness to a person yet not doubt the identity of that person, even if that person is one's father, so that the person might say, "Dad seems strangely unfamiliar to me." Thus, an alteration in one's sense of personal relatedness alone is not sufficient to produce a misidentification patient.

If the bodily self and the relational self are two separate, different parts of our sense of self, why is somatoparaphrenia similar to Capgras syndrome? One way that Feinberg could support the idea of a neutral-personal dichotomy is to generate more evidence for his claim that the personal confabulations are more enduring and refractory to correction than neutral confabulations. However, this may be true of beliefs about ourselves in general. It would be helpful to compare Feinberg's conception of the self with some others such as that of Damasio (1999) or of Gazzaniga's (1995) left-brain interpreter, or relate it to Newen and Vogeley's (2003) classification of the different types of self-representations.

\section{The two-factor approach}

One competing approach is called the two-factor account (Davies, Coltheart, Langdon, \& Breen, 2001; Langdon \& Coltheart, 2000). According to this approach, the patients' delusions are the product of two separate kinds of damage to their cognitive systems. The first factor tends to be caused by damage to the posterior of the cortex, while the second factor is caused by damage to executive processes housed in the brain's prefrontal lobes. In the case of anosognosia for hemiplegia, for instance, rather than postulating, as Feinberg does, that "there is a wide range of asomatognosic response, from simple unawareness or confusion regarding the ownership of the limb to delusional denial and confabulation about its identity," the two-factor approach breaks this continuum into two discrete parts. The unawareness or confusion occurs when the first factor is present - in this case, damage to somatosensory systems - while the second factor, damage to the brain's prefrontal executive processes, is not. Sustained confabulation and denial require the presence of the second factor.

One candidate for the first factor in Capgras syndrome is damage to our brains' systems devoted to understanding the minds and personalities of other people (Hirstein, 2005, 2010). As Capgras patient JH said, when it was pointed out that the women he claimed was not his mother looked exactly like an older photo of a woman he did acknowledge as his mother, "It's not the outside, it's the inside." An impos- tor is someone who visually resembles a person, while having a different identity, a different mind from that person. Capgras patients will sometimes point out differences in outward appearance between the impostor and the real person, but these tend to have the ring of confabulations. One patient claimed that she could tell her husband had been replaced because the new person tied his shoelaces differently, while another patient said that the impostor of her son "had differentcolored eyes, was not as big and brawny, and that her real son would not kiss her" (Frazer \& Roberts, 1994). A blind Capgras patient said that the impostor's hand felt softer than his mother's (Rojo, Caballero, Iruela, \& Baca, 1991). Some patients admit that they cannot find any external difference. Our patient DS said that the impostor looked "exactly like my father." One Capgras patient, author Clifford Beers, is clear that he searched for visual differences in order to confirm a preexisting belief that this was a different person. When relatives came to see him, he said, "I was able to detect some slight difference in look or gesture or intonation of voice, and this was enough to confirm my belief that they were impersonators" (Beers, 1953). Beers thought he detected slight differences, as many patients do, but noticed that during the delusional phase he regarded these as confirmatory of a preexisting belief that the person he was looking at was a different person.

The crucial posterior damage site for misidentification syndromes (in addition to prefrontal damage causing executive failures) may be a cortical area called the temporoparietal junction (TPJ). Cotard's syndrome, in which other people appear empty and hollow, as mannequins or robots, may be due to complete damage to the patient's ability to represent people as having minds. Two Cotard's syndrome patients studied by Young and his colleagues (Young, Leafhead, \& Szulecka, 1994; Young, Robertson, Hellawell, de Pauw, \& Pentland, 1992) had temporoparietal contusions along with bilateral frontal damage. The Capgras patient of Staton, Brumback, and Wilson (1982) showed "moderate atrophy . . . at the temporo-parietal junction." Similarly, a Capgras' patient seen by Johnson and Raye (1998) had a right temporoparietal hematoma. A Fregoli syndrome patient described by Feinberg, Eaton, Roane, and Giacino (1999) also had damage at the TPJ.

The TPJ has been found to be active during several "theory-of-mind" tasks, in which subjects attempt to understand the actions and motives of others. In a typical task, the brain of a subject is scanned as she or he observes people performing intentional actions, or evincing certain emotions. In one such experiment, the right TPJ's activity level was observed to be high when 
"participants read stories that describe a character's beliefs but low during stories containing other socially relevant information" (Young \& Saxe, 2009). It is also relevant that the right TPJ activates more strongly when the target person has beliefs that are known by the subject to be false (Young \& Saxe, 2009). Saxe describes the TPJ as an "area for representing mental states" (2006) that responds selectively to "the attribution of mental states" (Saxe \& Wexler, 2005) and plays a role in developing an "integrated impression" of people. I have argued that damage to the TPJ of Capgras patients disrupts their representations of the minds and personalities of their loved ones. It produces the appearance of a familiar body housing an unfamiliar mind (Hirstein, 2009, 2010).

One reason for postulating a second factor-malfunction of prefrontal executive processes - is that it is intended to explain why the patients do not notice the absurdity and implausibility of their claims (Coltheart, 2007; Turner \& Coltheart, 2009). Instead of this second factor, Feinberg says that "there is a disturbance in a firm and stable sense of personal identity and a perturbation in ego boundaries." But why does the patient not react to these disturbances in a normal way and, instead, posit bizarre "explanations"? Feinberg's response is that the patient adapts to the deficits in a "psychologically regressed fashion." But is this intended to cover both the first and second factors? The data from case studies tend to support a two-lesion theory of Capgras syndrome, with a more posterior lesion and a more frontal one (Signer, 1994).

The phenomenon of imaginary friends also contains this mindreading component. Children develop imaginary friends when they develop the ability to create representations of the minds of others. An imaginary friend is a mind that happens not to have a corresponding body. Similarly, phantom boarders and possibly some reports of ghosts are due to the pronounced presence to the perceiver of minds in a space, without the usual accompanying perception of bodies, according to this approach.

\section{The neuropsychology of the syndromes}

The section on the neuroanatomy of the syndromes is valuable because it gives us a way to save the insights of Freud by connecting them with neuroscience. The right hemisphere is certainly implicated in these syndromes, but that only narrows down the field by half. Feinberg notes that right frontal damage is frequently found, but what about the cases of damage near the TPJ noted above? Feinberg notes that in his study of the neuroanatomy of asomatognosia the patients had "significant temporoparietal involvement, but we found that the subgroup of [asomatognosic] patients with somatoparaphrenia had the largest lesions overall and significantly more frontal involvement." This fits the two-factor approach nicely: the temporoparietal damage distorts the patient's body image, and the frontal damage prevents him from realizing how odd it is to disown one's own arm. But as we saw above, Capgras syndrome can also involve temporoparietal damage. An account of the function of the temporoparietal cortex needs to be developed that explains this link.

\section{Final comments and conclusion}

This section contains some miscellaneous points followed by concluding remarks. Schnider's (2009) classification of subtypes of confabulation is rather like classifying cars into fast ones, red ones, old ones, and German ones. There is massive overlap between themnotice that any of the other three types could easily occur in the context of a conversation or in response to a question. Feinberg suggests that provoked, momentary, and behaviorally spontaneous confabulations are neutral, according to this personal-neutral dichotomy, but doesn't this depend on the content of those confabulations? A terminological point- -"personal identity"-is a term from the history of philosophy that refers to those features of a person that maintain her or his identity over time. As philosophers use the term, it need not have any psychological import to it. The adjective "personal" refers to persons in general, not to items we regard as uniquely our own or as definitive of us, as Feinberg uses the term. Perhaps another term should be coined to avoid confusion.

Feinberg argues that Capgras syndrome is multimodal, and the great majority of cases seem to be so, although this has not been systematically studied. However, our patient DS showed a clear modality specificity. He only believed his parents were impostors when he saw them in person (Hirstein \& Ramachandran, 1997). When speaking to them over the phone, he acknowledged their identity. Just as its mirror-image syndrome, prosopagnosia (inability to recognize familiar faces), occurs in the visual modality, while phonagnosia (inability to recognize familiar voices) occurs in the auditory modality, there may be modality-specific Capgras. The presence of Capgras syndrome in blind patients presumably occurs because the representations of the person's voice are not making contact with some more general representation associated with that person's identity. It may be that a portion of the pre- 
cuneus contains these "person identity nodes" (Campanella \& Belin, 2007; Shah et al., 2001), that can be accessed either visually or auditorily.

What is most important about Feinberg's approach is the way that it starts to make the incomprehensible understandable. What were previously treated as colorful reports of delusions can now be placed in a paradigm that relates them both to our psychologies and to the brain itself. This new paradigm also suggests new treatment techniques. Feinberg's position is midway between more classical Freudian or other psychiatric theories - which seek to understand these syndromes by a sort of logic or semantics they are posited to contain-and purely mechanistic theories-which attribute the symptoms to malfunctions of brain systems. A dialogue between Feinberg's account and more mechanistic accounts such as the two-factor theory promises to enrich both and bring more understanding to these syndromes so that ultimately effective treatments can be developed.

\section{REFERENCES}

Beers, C. W. (1953). A Mind That Found Itself: An Autobiography (7th edition). New York: Doubleday.

Campanella, S., \& Belin, P. (2007). Integrating face and voice in person perception. Trends in Cognitive Sciences, 11 (12): 535-543.

Coltheart, M. (2007). The 33rd Bartlett Lecture: Cognitive neuropsychiatry and delusional belief. Quarterly Journal of Experimental Psychology, 60: 1041-1062.

Damasio, A. R. (1999). The Feeling of What Happens: Body and Emotion in the Making of Consciousness. New York: Harcourt Brace.

Davies, M., Coltheart, M., Langdon, R., \& Breen, N. (2001). Monothematic delusions: Toward a two-factor account. Philosophy, Psychiatry, and Psychology, 8 (2-3).

Ellis, H. D., \& Young, A. W. (1990). Accounting for delusional misidentifications. British Journal of Psychiatry, 157: 239-248.

Feinberg, T. E., Eaton, L. A., Roane, D. M., \& Giacino, J. T. (1999). Multiple Fregoli delusions after brain injury. Cortex, 35: 373-387.

Frazer, S. J., \& Roberts, J. M. (1994). Three cases of Capgras' syndrome. British Journal of Psychiatry, 164: 557-559.

Gazzaniga, M. S. (1995). Consciousness and the cerebral hemispheres. In: The Cognitive Neurosciences, ed. M. S. Gazzaniga. Cambridge, MA: MIT Press.
Hirstein, W. (2005). Brain Fiction: Self-Deception and the Riddle of Confabulation. Cambridge, MA: MIT Press.

Hirstein, W. (2009). Confabulations about people and their limbs, present and absent. In: The Oxford Handbook of Philosophy and Neuroscience, ed. J. Bickle. Oxford: Oxford University Press, pp. 473-512.

Hirstein, W. (2010). The misidentification syndromes as mindreading disorders. Cognitive Neuropsychology, 15 (1-3): 233-260.

Hirstein, W., \& Ramachandran, V. S. (1997). Capgras syndrome: A novel probe for understanding the neural representation of the identity and familiarity of persons. Proceedings of the Royal Society of London, B, 264: 437-444.

Johnson, M. K., \& Raye, C. L. (1998). False memories and confabulation. Trends in Cognitive Sciences, 2: 137-145.

Langdon, R., \& Coltheart, M. (2000). The cognitive neuropsychology of delusions. Mind and Language, 15: 184-218.

Newen, A., \& Vogeley, K. (2003). Self-representation: Searching for a neural signature of self-consciousness. Consciousness and Cognition, 12: 529-543.

Rojo, V. I., Caballero, L., Iruela, L. M., \& Baca, E. (1991). Capgras' syndrome in a blind patient. American Journal of Psychiatry, 148 (9): 1271-1272.

Saxe, R. (2006). Uniquely human social cognition. Current Opinion in Neurobiology, 16: 235-239.

Saxe, R., \& Wexler, A. (2005). Making sense of another mind: The role of the right temporo-parietal junction. Neuropsychologia, 43: 1391-1399.

Schnider, A. (2009). The Confabulating Brain. Oxford: Oxford University Press.

Shah, N. J., Marshall, J. C., Zafiris, O., Schwab, A., Zilles, K., Markowitsch, H. J., et al. (2001). The neural correlates of person familiarity. A functional magnetic imaging study with clinical implications. Brain, 124: 804-815.

Signer, S. F. (1994). Localization and lateralization in the delusion of substitution. Psychopathology, 27 (3-5): 168-176.

Staton, R. D., Brumback, R. A., \& Wilson, H. (1982). Reduplicative paramnesia: A disconnection syndrome of memory. Cortex, 18: 23-36.

Turner, M., \& Coltheart, M. (2009). Confabulation and delusion: A common monitoring framework. Cognitive Neuropsychiatry, 15 (1-3): 346-376.

Young, A. W., Leafhead, K. M., \& Szulecka, T. K. (1994). Capgras and Cotard delusions. Psychopathology, 27: 226231.

Young, A. W., Robertson, L. H., Hellawell, D. J., de Pauw, K. W., \& Pentland, B. (1992). Cotard delusion after brain injury. Psychological Medicine, 22: 799-804.

Young, L., \& Saxe, R. (2009). An fMRI investigation of spontaneous mental state inference for moral judgment. Journal of Cognitive Neuroscience, 21 (7): 1396-1405. 